\title{
Design and Implementation of an Online Course Management System
}

\author{
Emmanuel N. Ekwonwune1, Dominic C. Edebatu ${ }^{2}$ \\ ${ }^{1}$ Department of Computer Science, Imo State University, Owerri, Nigeria \\ ${ }^{2}$ Department of Computer Science, Nnamdi Azikiwe University, Awka, Nigeria \\ Email: ekwonwuneemmanuel@yahoo.com
}

How to cite this paper: Ekwonwune, E.N. and Edebatu, D.C. (2019) Design and Implementation of an Online Course Management System. Journal of Software Engineering and Applications, 12, 21-33. https://doi.org/10.4236/jsea.2019.122002

Received: July 31, 2018

Accepted: February 24, 2019

Published: February 27, 2019

Copyright (c) 2019 by author(s) and Scientific Research Publishing Inc. This work is licensed under the Creative Commons Attribution International License (CC BY 4.0).

http://creativecommons.org/licenses/by/4.0/

(c) (i) Open Access

\begin{abstract}
Learning abilities vary among individuals, yet schools teach them in one classroom. Managing learning abilities could be difficult. This Online Course Management System integrates learning techniques which addresses this problem. The aim of this work therefore is to develop an adaptative e-Learning Software to enable the learner answer questions or solve problems based on his/her ability. This work is motivated by the need to address deep concern and awareness toward how learners learn best. This study develops an adaptive e-learning platform where the learner is allowed to answer questions or solve problems based on his/her ability or pace. It also provides an online classroom which will run alongside the traditional classroom. The software will adopt the waterfall model. VB.NET, an Object Oriented Programming Language will be used with AJAX and JAVASCRIPT web development tools. Furthermore, this study recommends new strategies \& technologies to improve safety, quality, and overall standard of learning amongst learners in educational institutions.
\end{abstract}

\section{Keywords}

Online, E-Learning, Management, Technology, Internet

\section{Introduction}

The generation of students born with digital technology brings with them a significantly different approach to learning [1]. They are used to having access to multiple and instantaneous sources of information, multitasking and being socially connected to peers through mobile devices. The combination of mobile technologies and the new generation's digitally-enhanced' cognitive and social skills will need new solutions in the current concept of Learning. 
One potential solution is mobile learning. M learning is the exploitation of ubiquitous handheld technologies, together with wireless and mobile phone networks, to facilitate, support, enhance and extend the reach of teaching and learning [2]. It offers enormous potential as a tool to be used in situations where learners are geographically dispersed, to promote collaborative learning, to engage learners with content, as an alternative to books or computers, as an alternative to attending campus lectures and for "just-in-time" delivery of information. With mobile technology, we can "push" and "pull" information and deliver learning to any one at any time and at any place. It provides learning on-the-go or just-in-time learning [3]. The significance of education, especially in developing countries, is increasing because of progressing pressure to catch up with the developed world regarding, for example, global competitiveness [4]. Some of the areas of improvement in developing countries include: provision of standardized computer-based tests, qualified facilitators, adequate learning environment, standard textbooks, digital library, computerized student assessment, and sporting facilities, among others.

It is obvious that computers have significantly increased the range, sophistication, and complexity of possible classroom activities. Computer-based technology has also brought with it many new challenges for the teacher who seeks to determine what it has to offer and how that should be delivered to students.

The incorporation of information technology in education has brought so many positive changes. Today, more academic systems are embracing technology, because it makes teaching more effective and aids in practical learning. Students are embracing it because in the future, most of the jobs will be technologically based. With time, everyone will see the significance of information technology in education.

This work examines the use of technology in teaching and learning. It also designs and implements an online course management system that incorporates instant search algorithm, evaluations and assessments and a reliable application portal for teachers, learners and parents.

Since the dawn of the $21^{\text {st }}$ century, technology has crept its way into learning and teaching environments. As more technological advancements are made, then there is dire need for increased literacy levels on the use of this technology. Earlier, technology in education was a debatable topic amongst the society. Everyone had their own views on modernizing education and making it technology aided. There were a huge number of positives and negatives to education technology. But, gradually as technology was embraced by the educational institutions, they realized the importance of technology in education. Its positives outnumbered the negatives and now, with technology, education has taken a whole new meaning that it leaves us with no doubt that our educational system has been transformed owing to the ever-advancing technology. Technology and education are a great combination if used together with a right reason and vision. 


\subsection{Statement of Problem}

The problems associated with the system under study are outlined below:

1) Learning abilities vary among learners, yet teachers teach them the same content, in one classroom.

2) Learners are evaluated and accessed equally, although learners do not have the same equal learning abilities.

3) Teachers or facilitators evaluate their students using questions which are out of context most of the times.

4) Learning does not cover the three domains of education which are the cognitive, affective and psychomotor levels.

5) There is absence of an online classroom running alongside the traditional classroom, which limits learning to during school hours only.

\subsection{Aim and Objectives of Study}

The aim of this work is to develop an adaptive e-learning software to enable the learner to answer questions or solve problems based on his/her ability or pace. The objectives of this study are to:

1) Develop web based tool for managing learners' courses.

2) Integrate a feature which will enable learners to schedule reminders for their assignments or evaluations.

3) Develop a feature which will be used to make sure that all the levels of learning are covered.

4) Design and integrate a feature which will enable learners to answer questions based on their learning abilities for evaluations.

\section{Theoretical Framework}

E-Learning has many interpretations but in short it stands for learning by electronic means. This means learning not directly from lecture notes, books or face-to-face from teacher but through electronic means. Common forms are computer-based training and web based lessons or on-line lessons. With the advent of advanced technology, lessons may be taken anytime anywhere in a remote area. In this work I will be looking at some concept, technologies, and challenges of e-learning in Nigerian Universities.

[5] defined it as the use of internet and digital technologies to create experiences that educate our fellow human beings.

The Internet has become one of the vital ways to make available resources for research and learning for both teachers and students to share and acquire information.

Technology-based e-learning encompasses the use of the internet and other important technologies to produce materials for learning, teach learners, and also regulate courses in an organization [6]. There has been extensive debate about a common definition of the term e-learning. Existing definitions according to [7] tend to reveal the specialization and interest of the researchers. E-learning as a 
concept covers a range of applications, learning methods and processes [8]. It is therefore difficult to find a commonly accepted definition for the term e-learning, and according to [9], there is even no common definition for the term. [10] also made a comment on these inconsistencies by saying that there may be as many definitions of the term e-learning as there are academic papers on the subject [7] in trying to find a common meaning of the term e-learning went on to ask the following questions: Is e-learning an on-line coursework for students at a distance? Does it mean using a virtual learning environment to support the provision of campus based education? Does it refer to an on-line tool to enrich, extend and enhance collaboration? OR is it a totally on-line learning or part of blended learning? [11]. Some of the definitions of the term e-learning as given by different researchers and institutions are reviewed below.

In some definitions e-Learning encompasses more than just the offering of wholly on-line courses. For instance [9] noted that e-Learning has transformed from a fully-online course to using technology to deliver part or all of a course independent of permanent time and place. Also the [12] describes, e-Learning as the use of new multimedia technologies and the Internet to increase learning quality by easing access to facilities and services as well as distant exchanges and collaboration. The following are also different definitions of e-learning.

E-learning refers to the use of information and communication technologies to enable the access to online learning/teaching resources. In its broadest sense, [13] defined E-learning to mean any learning that is enabled electronically. They however narrowed this definition down to mean learning that is empowered by the use of digital technologies. This definition is further narrowed by some researchers as any learning that is internet-enabled or web-based [14] [15].

According to [16], the term "e-learning" is applied in different perspectives, including distributed learning, online-distance learning, as well as hybrid learning. E-learning, according to [17] is defined as the use of information and communication technologies in diverse processes of education to support and enhance learning in institutions of higher education, and includes the usage of information and communication technology as a complement to traditional classrooms, online learning or mixing the two modes. Also according to [18] the term e-learning refers to the attainment and use of knowledge that are predominantly facilitated and distributed by electronic means. To them, the e-learning depends on computers and networks, but it is likely it will progress into systems comprising of a variety of channels such as wireless and satellite, and technologies such as cellular phones.

According to [19], this new environment for learning that is centered on electronic networks has allowed learners in universities to receive individualized support and also to have learning schedules that is more suitable to them as well as separate from other learners. It is apparent that e-learning can empower students at higher educational levels to acquire their education in while at the same time perusing their personal objectives as well as maintaining their own careers, with no need to attend be subjected to rigid schedule [20]. [21] in support of this 
thought reported that the number of courses online has vividly increased as a result of the attained benefits for both learners and universities.

It can therefore be concluded from the above that it is difficult to identify a common definition for e-learning. Some of the authors refer to e-learning as providing complete on-line courses only whereas comprise web-supplemented and web-dependent services for the provision of educational and support processes

\subsection{MOODLE E-Learning Technology}

MOODLE is a free software package designed to help lecturers and students as a tool to provide in of quality teaching. The MOODLE is abbreviated to Modular Object Oriented Dynamic Learning Environment built by Martin Douglas at Curtin University [22].

MOODLE has a number of advantages in education. MOODLE is easy to install, upgrade and use. It can be installed on as many servers as involved without an additional cost. MOODLE does not also require modification on Unix, Linux, Windows, Mac OS and any other systems [23]. It is implemented for educational aspects which some other e-learning platform is lack off.

\subsection{Challenges/Problems Facing E-Learning Today}

If E-Learning is to live up to its expectations in any nation, place or institution, it must overcome Technologically, Socially and Pedagogically aspects including the change of mindset is required. These restraints must be overcome before implementing E-Learning. According to [24] the challenges are as follows:

1) Technological aspect; 2) Social aspect; 3) Pedagogical aspect: Mindset aspect; 4) Lack of face-to-face interaction; 5) Technical Training Challenges.

\subsubsection{Challenges of E-Learning Technologies in Nigerian Universities}

E-learning technologies development is faced with a lot of challenges in Nigerian Universities. One of these challenges is inability of teachers to assist the students develop the ability and knowledge necessary to make them use the e-learning effectively.

In many e-learning projects, students face some challenges of bad perception during their studies; lack of pedagogy in their curriculum, lack of user touch and feel in their e-learning platform [25].

Four obstacles affecting the total implementation of e-learning in developing countries are:

1) Connectivity; 2) Equipment; 3) Software; 4) Training.

\subsubsection{Advantages/Benefits of E-Learning: They Include}

1) Flexibility; 2) Convenience; 3) E-learning Approaches 4) Self-paced e-learning; 5) Instructor-led and facilitated e-learning.

\section{Methodology}

The waterfall model was used. The waterfall model is a linear sequential (non-iterative) 
design approach for software development, in which progress flows in one direction downwards (like a waterfall) through the phases of conception, initiation, analysis, design, construction, testing, deployment and maintenance. It will be used because it allows for departmentalization and managerial control.

\subsection{Waterfall Model Overview}

The Waterfall Model was first Process Model to be introduced. It is very simple to understand and use.

As shown in Figure 1, before the next phase can begin and there is no overlapping in the phases.

The sequential phases in Waterfall model are:

1) Requirement Gathering and analysis; 2) System Design; 3) Implementation Integration and Testing; 4) Deployment of system; 5) Maintenance.

\subsection{Mode of Operation}

Lectures at Imo State Polytechnic Umuagwo, are currently carried out in the traditional classroom. There is no provision for learning online, outside the traditional classroom. However, the lecturer instructs students physically in a typical

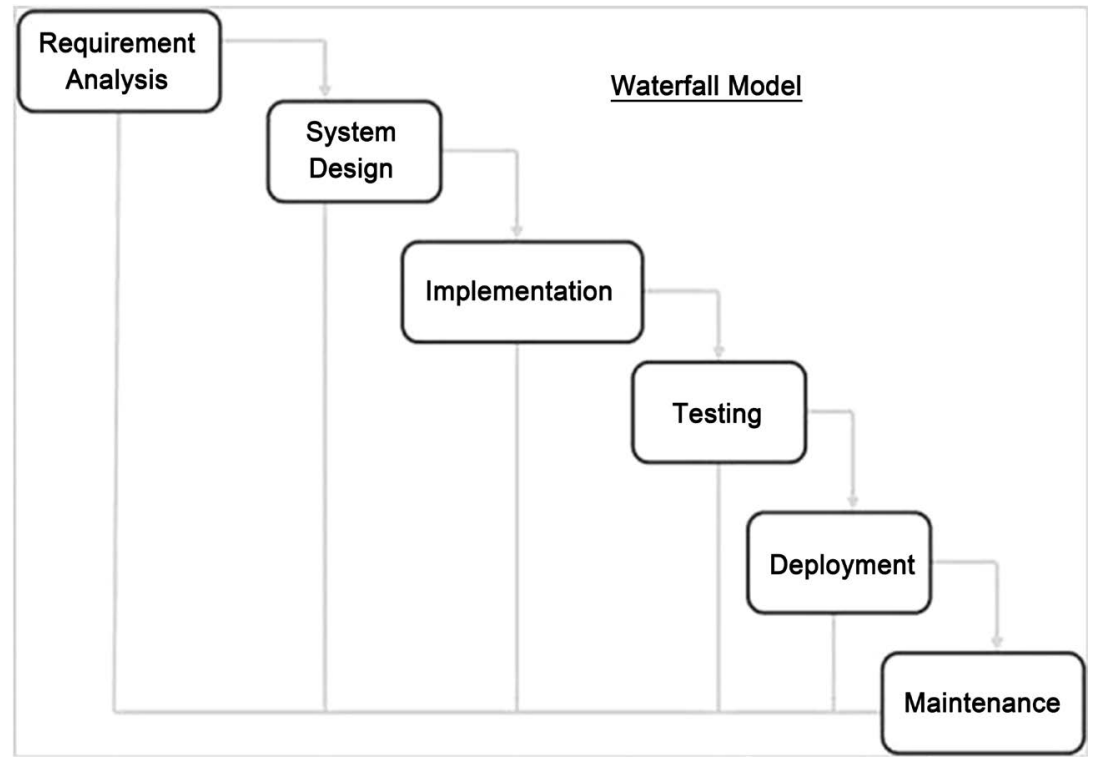

Figure 1. Stages of waterfall model (Source: tutorials point 2017).

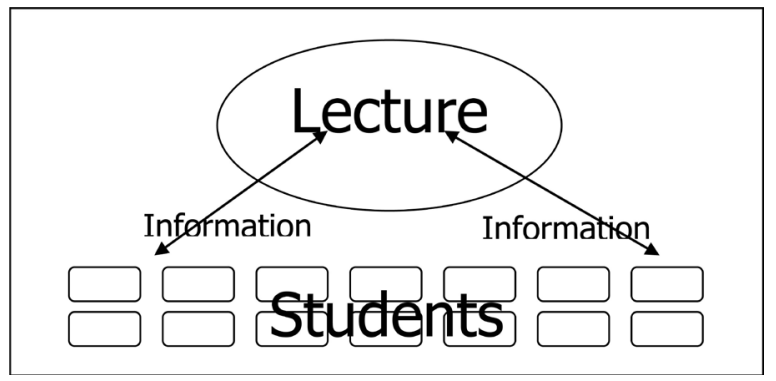

Figure 2. Operations/Information Flow Source: (Field Work, 2018). 
classroom. Questions are entertained and responses are shared. Learning is one-sided in some cases because lecturers may decide to just read handouts to students and end the class (see Figure 2 above).

\subsection{Expectations of the New System}

This new system, when adopted will do the following:

1) Ensure that student evaluation questions are not out of context, and covers the three domains of learning.

2) Manage learners' courses effectively.

3) Integrate a feature which will enable learners to schedule reminders for their assignments or evaluations.

4) Develop a feature which will be used to make sure that all the levels of learning are covered in a course.

5) Ensure that learners answer questions based on their learning abilities for evaluations.

\subsection{High Level Model of the Proposed Software}

Figure 3 below shows the high level model of the proposed system. MySQL

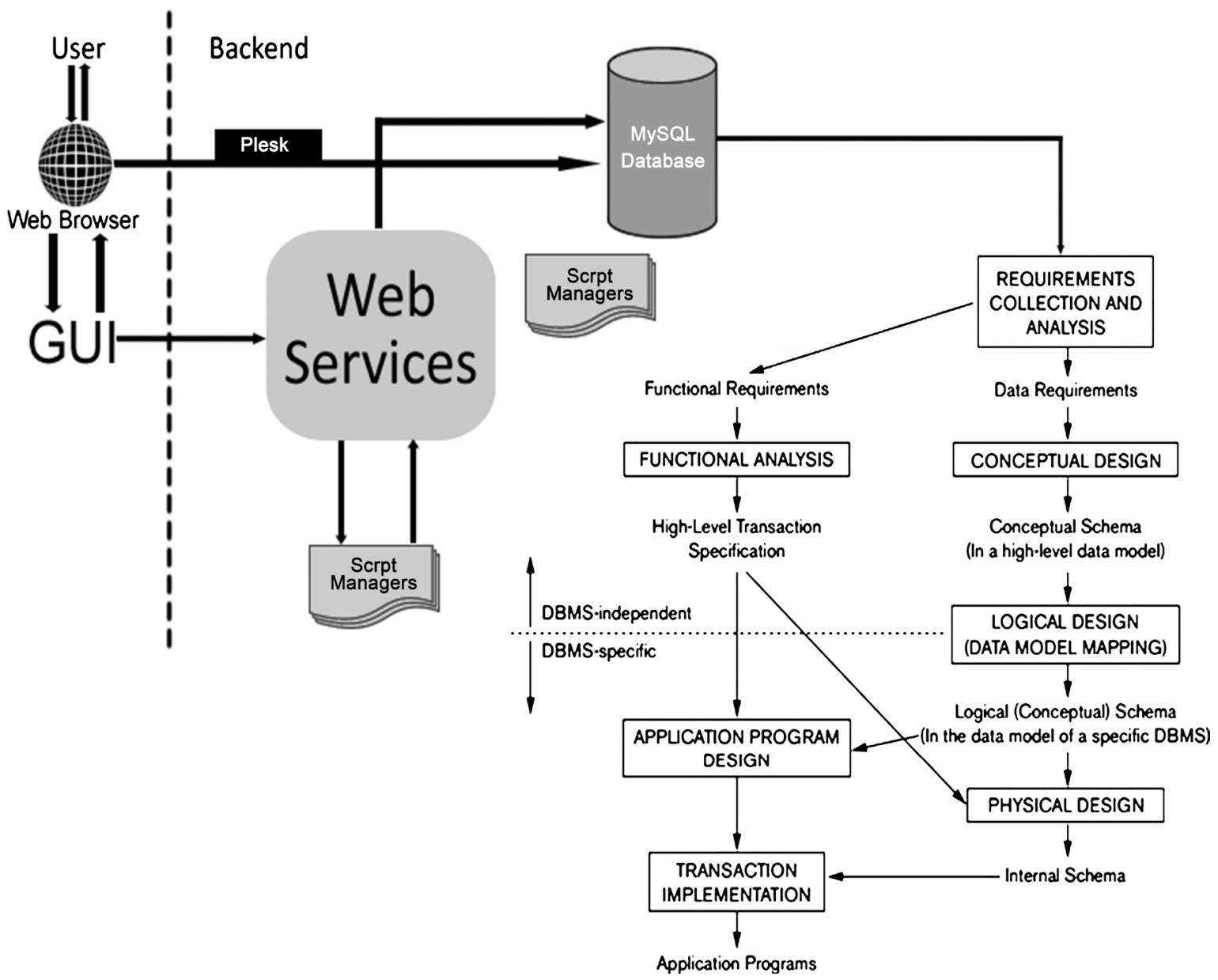

Figure 3. HLM of the proposed system (Source: Field work, 2018). 
Relational Database Management Program will be used at backend.

\section{Program/System Design}

In this context, the definition of the architecture, components, modules, interfaces and data for the new system will be made as shown in Figure 4.

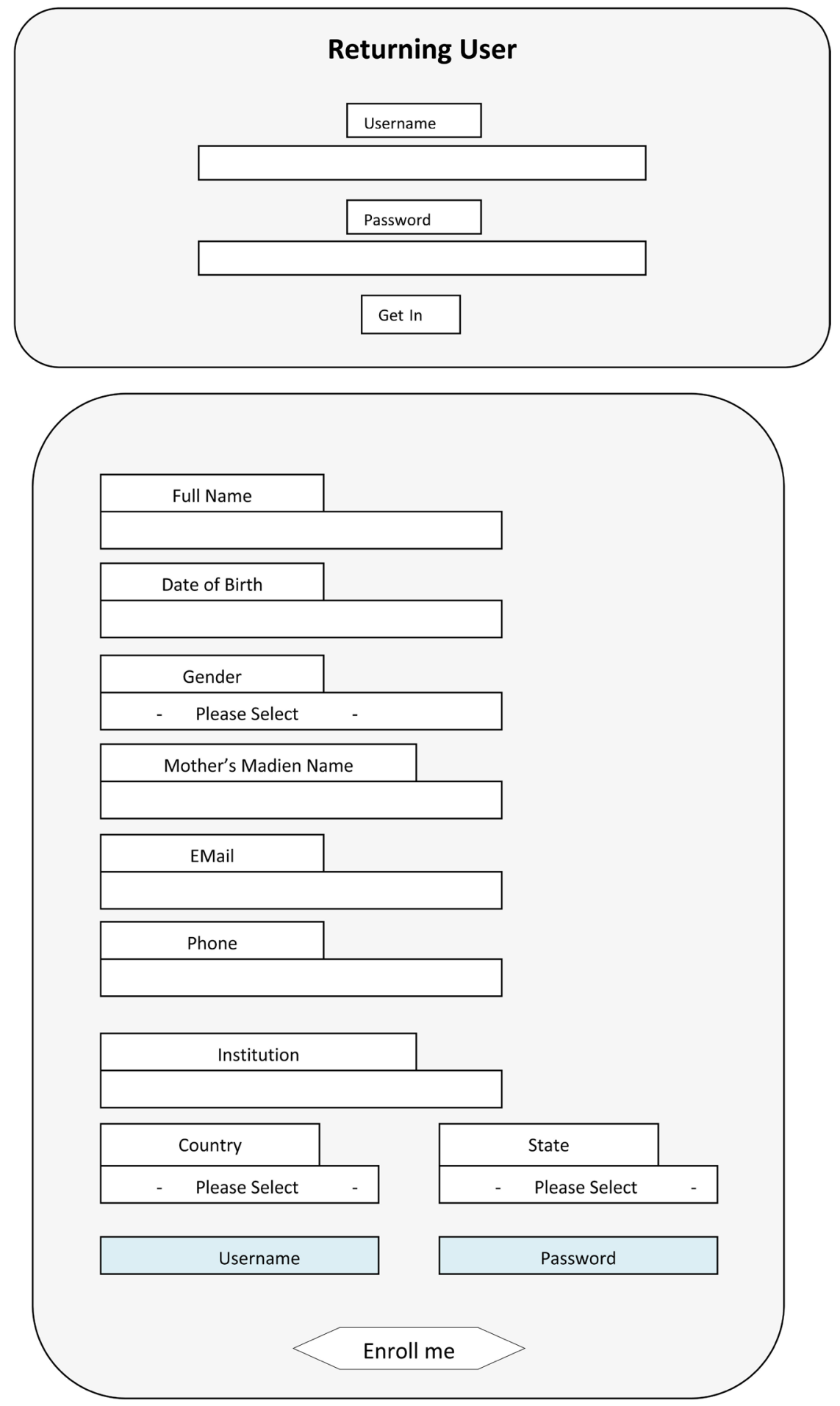

Figure 4. Home page: Source: (Field Work, 2018). 
1) Home Page: This is the first page a user sees when the web application is launched. Registered or returning users can log into the program with the enrolled username and password. New users can enroll if they have not been previously registered.

2) Welcome Page: this is displayed on successful login attempt. User session is created for each user on successful authentication.

Here, users can view and populate their courses for a current semester. They can populate course contents, and schedule reminders for submission of assignments or upcoming evaluations.

\subsection{Algorithms}

This refers to step-by-step descriptions of the solutions to problems. The Flowchart shown below is a clear indication of how the user interacts with developed system. It shows the welcome page which allows the user to enter username/password. The Decision Symbol requests whether the Username exists or otherwise. Subsequently, the process continues (see Figure 5 below).

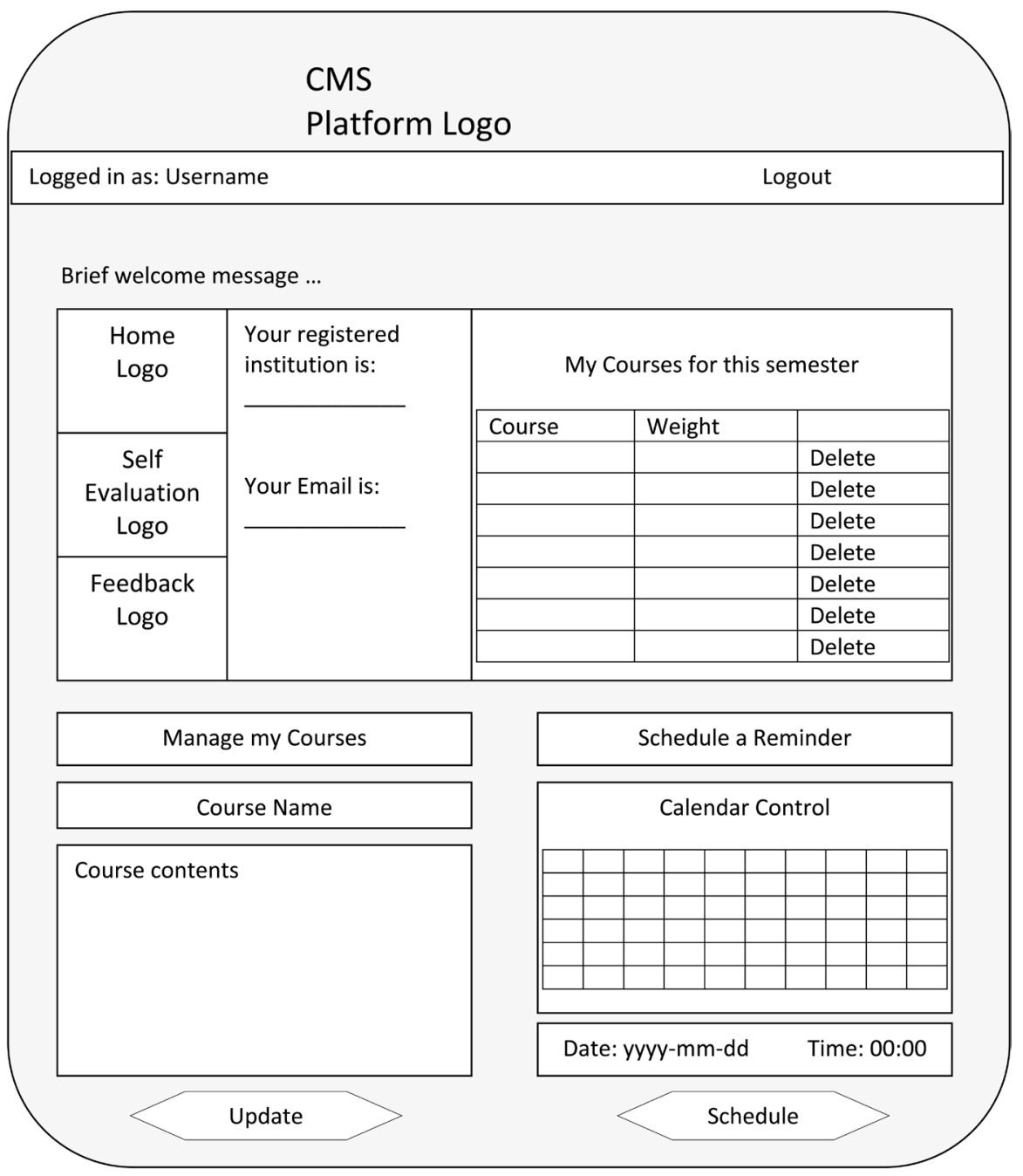

Figure 5. Welcome page: Source: Field Work. 


\subsection{System Requirements}

\subsubsection{Hardware Requirements}

The following hardware components should be made available for full operation and performance:

1) A hard disk drive of about 80 (GB) and above.

2) A Pentium $\mathrm{M}(2.0 \mathrm{GHz})$ processor.

3) A flat screen monitor.

4) A RAM of at least 1.0 GB and above.

5) An enhanced keyboard.

6) A printer.

7) A UPS.

8) Flash drives for backup files.

\subsubsection{Software Requirements}

This refers to all programs, which the computer needs to execute a complete process. For this software to run without any hitch, the following have to be installed:

1) An Operation system, Microsoft Windows (XP, 7 or 8); 2) Dot Net framework 3.0, 3.5, 4.0 or 4.5; 3) Reliable antivirus software; 4) MySQL Database program.

\subsection{Input/Output Design}

The aim of design in any system development is to make data entry easy, and logical flow-charts free from errors. There is need for the operator to know the following during the entry (see Figure 6 below):

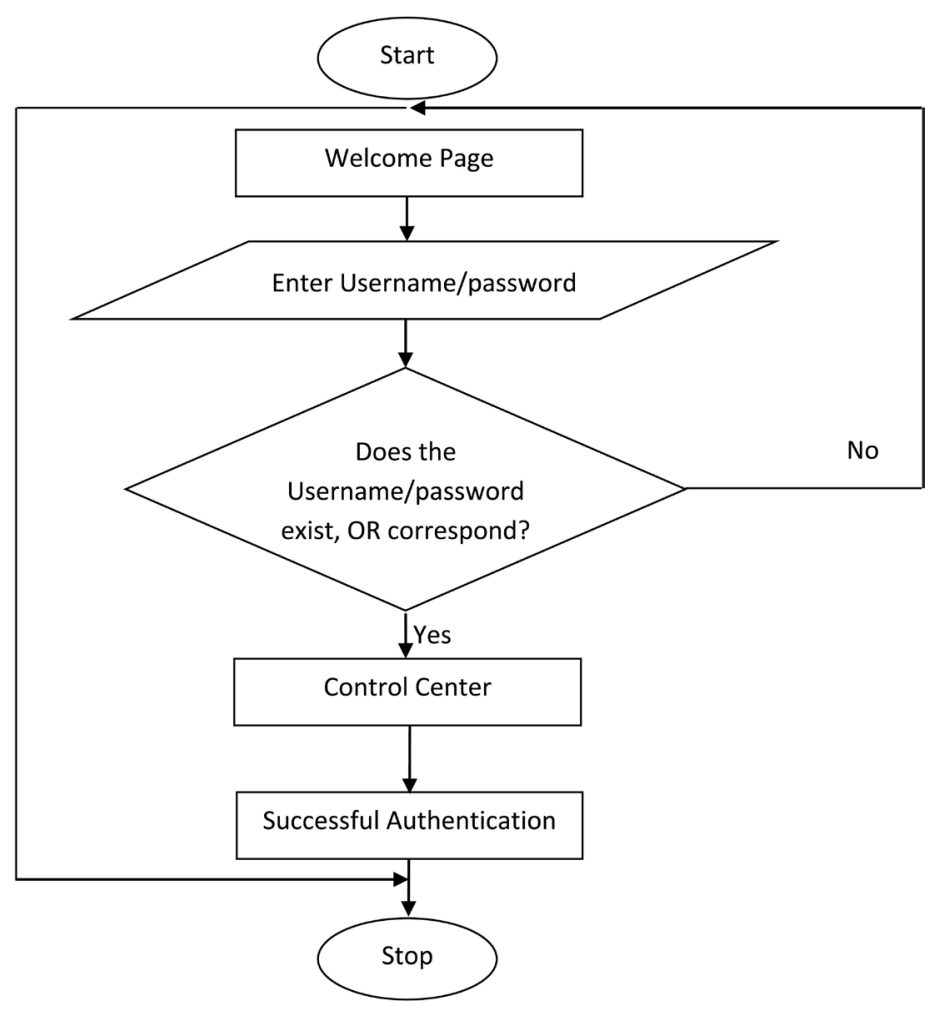

Figure 6. Home PageSource: (Field work, 2018). 
1) The space allocated to each field.

2) Field sequence, which must correspond to that in the source document.

3) The format in which the data are entered.

The validity of the input determines the accuracy of the output. The input presented must be as accurate as possible. This should be monitored so that illegal/wrong data would not be entered.

\section{Conclusions}

E-learning is becoming more popular day after day due to the rapid technological advancements made especially in ICT. Disappointedly, the under-developed countries are yet to implement e-learning effectively, for the acquisition of education, knowledge, skills and training. This is partly because of the inadequacy of the required infrastructure and the improper attention given to its impact. Although most of the tertiary institutions had already commenced the use of e-learning, it is mostly implemented for administrative purposes, such as examination and learning purposes.

This research work, therefore, attempted in creating three web-based, CAL application software, e-book, and videos on various courses to be taught by the lecturer which will be both affordable by the users.

\section{Recommendation}

It is expected that this research work, if properly effected and handled, will promote the image of the department and improve the quality of service they render with respect to the impacting of knowledge to the students. This is based on the perspective that the work, if actualized, will serve as an outstanding example to the other departments of the institution and even to the indigenous tertiary institutions, students and lecturers.

\section{Conflicts of Interest}

The authors declare no conflicts of interest regarding the publication of this paper.

\section{References}

[1] Barbaux, M.-T. (2006) From Lifelong Learning to M-Learning. The 13th International Conference ALT-C2006: The Next Generation, Edinburgh, Scotland, UK.

[2] Vani Kalloo, H. and Permanand, M. (2012) Correlating Questionnaire Data with Actual Usage Data in a Mobile Learning Study for High School Mathematics, Electronic. Journal of e-Learning, 10, 76-89.

[3] Zoraini, W.A, Chng, L.P. and Norziati, M. (2009) A Study on Learner Readiness for Mobile Learning at Open University Malaysia. IADIS International Conference Mobile Learning, Barcelona, 26-28 February 2009, 151-157.

[4] Hawkins, B.L. and Rudy, J.A. (2007) Educause Core Data Service: Fiscal Year 2006 Summary Report. Educause, Boulder, CO. http://media.clemson.edu/ccit/assessment/Core_Data_Survey_Summary_Report_20 
06.pdf

[5] Horton, W. (2005) Leading E-Learning. ASTD, p. 1.

http://www.e-learningguru.com

[6] Fry, K. (2000) Forum Focus and Overview, the Business of E-Learning: Bringing Your Organization in the Knowledge Economy. Telcam Group, University of Technology, Sydney.

[7] Dublin, L. (2003) If You Only Look under the Street Lamps... Or Nine E-Learning Myths. The E-Learning Developers Journal. http://www.eLearningguild.com

[8] Rossi, P.G. (2009) Learning Environment with Artificial Intelligence Elements. Journal of E-Learning and Knowledge Society, 5, 67-75.

[9] Oblinger, D.G. and Hawkins, B.L. (2005) The Myth about E-Learning. Educause Review.

[10] Holmes, B. and Gardner, J. (2006) E-Learning: Concepts and Practice. SAGE Publications, London.

[11] Dublin (2005) Electronic Journal of E-Learning. https://www.ejel.org/

[12] European Commission (2000) Communication from the Commission: E-learning-Designing “Tejas at Niit” Tomorrow's Education. European Commission, Brussels.

[13] Abbad, M.M., Morris, D. and de Nahlik, C. (2009) Looking under the Bonnet: Factors Affecting Student Adoption of E-Learning Systems in Jordan. The International Review of Research in Open and Distance Learning, 10, No. 2. https://doi.org/10.19173/irrodl.v10i2.596

[14] La Rose, R., Gregg, J. and Eastin, M. (1998) Audio Graphic Tele-Courses for the Web: An Experiment. Journal of Computer Mediated Communications, 4, No. 2. https://doi.org/10.1111/j.1083-6101.1998.tb00093.x

[15] Keller, C. and Cernerud, L. (2002) Students' Perception of E-Learning in University Education. Learning, Media and Technology, 27, 55-67.

[16] Maltz, L., Deblois, P. and the EDUCAUSE Current Issues Committee (2005) Top Ten IT Issues. EDUCAUSE Review, 40, 15-28.

[17] OECD (2005) E-Learning in Tertiary Education. http://www.cumex.org

[18] Wentling, et al. (2000) E-Learning-A Review of Literature. Knowledge and Learning Systems Group NCSA 9.1-73.

[19] Tao, et al. (2006) Improving Training Needs Assessment Processes via the Internet: System Design and Qualitative Study. Internet Research, 16, 427-449. https://doi.org/10.1108/10662240610690043

[20] Borstorff, P.C. and Lowe, S.L. (2007) Student Perceptions and Opinions toward e-Learning in the College Environment. Academy of Educational Leadership Journal, 11, 13-30.

[21] Kartha, C.P. (2006) Learning Business Statistics vs. Traditional. Business Review, 5, 27-33.

[22] Rosato, J.C., et al. (2000) The Ethics of Clinical Trails: A Child's View. https://www.Journals.sagepub.com

[23] Alkhateeb, F., et al. (2014). E-Learning Tools and Technologies in Education: A Perspective. Researchgate.net.

https://www.researchgate.net/publication/228760740_E-learning_Tools_and_Techn ologies_in_Education_A_Perspective

[24] Bhandari (2015) Challenges Facing e-Learning Today. 
https://www.files.eric.ed.gov/

[25] Allen, I.E. and Seaman, J. (2003) Sizing the Opportunity; the Quality and Extent of Online Education in the United States, 2002 and 2003. The Sloan Consortium, Wellesley. 